\title{
HVMANITAS
}

\section{[Recensão a] Molina, Alejandro Bancalari - Orbe Romano e Imperio Global. La Romanización desde Augusto a Caracalla}
Autor(es):
Mantas, Vasco Gil Publicado por: $\begin{aligned} & \text { Faculdade de Letras da Universidade de Coimbra, Instituto de Estudos } \\ & \text { Clássicos }\end{aligned}$
URL persistente:
URI:http://hdl.handle.net/10316.2/27970
DOI:
DOI:http://dx.doi.org/10.14195/2183-1718_61_24

Accessed : $\quad$ 26-Apr-2023 10:48:38

A navegação consulta e descarregamento dos títulos inseridos nas Bibliotecas Digitais UC Digitalis, UC Pombalina e UC Impactum, pressupõem a aceitação plena e sem reservas dos Termos e Condições de Uso destas Bibliotecas Digitais, disponíveis em https://digitalis.uc.pt/pt-pt/termos.

Conforme exposto nos referidos Termos e Condições de Uso, o descarregamento de títulos de acesso restrito requer uma licença válida de autorização devendo o utilizador aceder ao(s) documento(s) a partir de um endereço de IP da instituição detentora da supramencionada licença.

Ao utilizador é apenas permitido o descarregamento para uso pessoal, pelo que o emprego do(s) título(s) descarregado(s) para outro fim, designadamente comercial, carece de autorização do respetivo autor ou editor da obra.

Na medida em que todas as obras da UC Digitalis se encontram protegidas pelo Código do Direito de Autor e Direitos Conexos e demais legislação aplicável, toda a cópia, parcial ou total, deste documento, nos casos em que é legalmente admitida, deverá conter ou fazer-se acompanhar por este aviso.

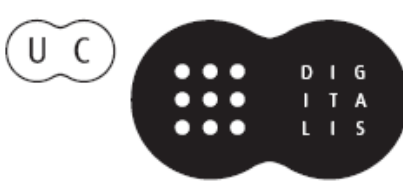


humanitas

\section{Vol. LXI}

IMPRENSA DA UNIVERSIDADE DE COIMBRA

COIMBRA UNIVERSITY PRESS 


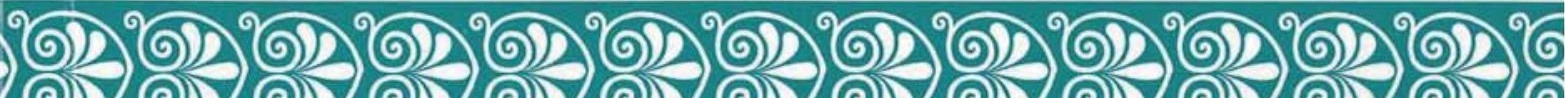

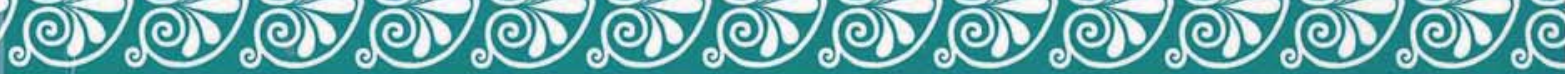

Vol. LXI 
vertente, a edição, tradução e notas couberam a Carlos Martins Jesus (mestre pela Faculdade de Letras de Coimbra, precisamente com a tradução e estudo de As Vespas) cujo papel junto do referido certame tem passado, ainda, pela encenação e mesmo pela representação, no âmbito do grupo Thiasos.

Hugo Pinto Santos

Molina, Alejandro Bancalari, Orbe Romano e Imperio Global. La Romanización desde Augusto a Caracalla, Santiago do Chile, Editorial Universitaria, 2007, 327 pp., ilustrado. ISBN: 978 - 956 $11-1974-1$

A imagem da deusa Roma, entronizada no Capitólio de Miguel Ângelo, tão perto da Basílica de Aracoeli e do Vitoriale, fez-me reflectir sobre o sentido da história romana e da ascensão e queda da Cidade Eterna. Esta reflexão, como é habitual, leva ao problema maior de tentar perceber as razões da queda da Roma Antiga, e a mesma incomodidade que acompanha esta questão, pelo menos desde as tentativas de explicação de Montesquieu e de Gibbon ${ }^{8}$, não deixou de se fazer sentir. A estátua de Roma e o cenário que continua a reger, sugeriram-me uma resposta para estas duas questões fundamentais da civilização europeia, ou, se quisermos, ocidental $^{9}$, atribuindo a perenidade de Roma à sua capacidade de transformação, a qual, em última análise, explica tanto a sua ascensão como a sua queda. O Império que desaparece em 476, do qual Roma já perdera a capitalidade, obriga a aceitar que esta Roma era já outra, muito diferente da que viu surgir o Império das águas ensanguentadas de Áccio. Talvez por isso foi possível falar de uma segunda e de uma terceira Roma, emanações do legado da primeira, mas muito diferentes entre si.

A obra que aqui apresentamos, sem procurar uma explicação para as causas da queda do Império, uma vez que o âmbito cronológico escolhido pelo autor não ultrapassa o governo de Caracala, trata de aspectos

${ }^{8}$ Charles de Montesquieu publicou Considérations sur les causes de la grandeur des Romains et de leur décadence em 1734; Edward Gibbon publicou a monumental The History of the Decline and Fall of the Roman Empire entre 1734 e 1788 .

${ }^{9} \mathrm{Ph}$. Nemo, O que é o Ocidente?, Lisboa, 2005. 
intrinsecamente relacionados com as questões referidas, constituindo um brilhante exercício sobre como o êxito pode conter os factores da própria destruição, ou, no mínimo, de uma evolução inesperada. O autor dedicou-se com entusiasmo a uma tarefa difícil, procurando fazer coincidir com o fenómeno da Romanização no Alto Império, complexo e com tempos de concretização diferenciados, os aspectos dominantes da muito falada globalização ${ }^{10}$. Bastaria a presença desta ideia, que atravessa toda a obra, para imediatamente despertar o interesse para a sua leitura, que exige concentração pela enorme quantidade de opiniões apresentadas e discutidas de forma a apoiar a tese defendida. Devo dizer que não há aqui novidade especial, pois as comparações com a civilização romana e a civilização internacional contemporânea, ainda que com sinal fortemente negativo, já se ouvem há várias décadas ${ }^{11}$, constituindo um sinal dos tempos e, simultaneamente, demonstrando como as ciências históricas são sensíveis ao ambiente ideológico e económico em que se desenvolvem.

A identificação entre os factores de Romanização que Alejandro Molina enumera e os que considera fundamentos da globalização conduzem o leitor à conhecida identificação entre os EUA e o Império Romano, através da sua capacidade de projecção de forças, não apenas militares, mas também, sobretudo, culturais, ideológicas e económicas, conformando uma espécie de lugar central da globalização. Esta é uma questão particularmente sensível, exigindo extrema cautela quando se pretende estabelecer relações entre a actuação de Estados separados por dois mil anos de História, com tudo o que isso significa. Recordamos, e bastante a propósito desta outra identificação surgiu há poucos anos um polémico livro de Bryan Ward-Perkins sobre o significado civilizacional da queda do Império Romano ${ }^{12}$, o recurso à imagem deste como paradigma da União Europeia, minimizando nesta identificação factores essenciais como a prática democrática e as características do centro político, sempre a cidade de Roma no período de que trata a obra do nosso colega chileno.

Por outro lado, e para que as aparências sejam conduzidas à sua escala e tempo reais, lembro que o período da história imperial posterior ao que Molina considera o triunfo da Romanização plena, com o governo de Caracala, em particular o que se inicia com a Tetrarquia, depois das convulsões

${ }^{10}$ M. Waters, Globalização, Oeiras, 1999.

${ }^{11}$ L. Mumford, The City in History, Londres, 1961, pp. 229-230, 242.

${ }^{12}$ B. Ward-Perkins, A queda de Roma e o fim da civilização, Lisboa, 2006. 
que marcaram profundamente o século III, assiste ao triunfo não do Estado Liberal, como seria lógico de acordo com o pensamento comparativista do autor, mas sim de um Estado Totalitário, intervencionista em todos os aspectos, completamente contrário ao que fora a regra vigente durante o Alto Império $^{13}$. Sem querer prolongar esta reflexão sobre o perigo de criar uma história alternativa através da modernização do passado, tão na moda por razões políticas, não deparamos já, aceitando que Washington herdou o papel de Roma, com o Ocidente dividido em dois impérios, com as respectivas capitais em Bruxelas e em Washington?

A obra conta um Prólogo, da autoria de Cesare Leta, docente na Universidade de Pisa, com uma Introducción e com cinco desenvolvidos capítulos: La Romanización como proceso histórico de larga duración: fundamentos teóricos; La teoría y el estudio de la Romanización: pluralidad de modelos; Grandes variables y factores del processo de Romanización; Distintos testimonios sobre el mundo romano; De Roma a la Aldea Global. Há ainda um Apéndice, que se ocupa das relações para além do Limes, significativamente abrangendo apenas as relações com a Índia e com a China, e várias páginas de Conclusiones. A bibliografia é muito vasta, ocupando trinta e quatro páginas, geralmente actualizada e contemplando títulos de sociologia e politologia pouco usuais em obras deste tipo. Como é natural, grande parte da bibliografia indicada é de língua italiana, castelhana e inglesa. Ocorre-me uma chamada de atenção a propósito da ausência de autores portugueses entre as obras consultadas, tanto mais que a obra alude repetidamente à Hispânia e mesmo à Lusitânia, faltando também muitas obras recentes directamente relacionadas com a província e com a sua capital. Esta ausência, que não pode deixar de se considerar preocupante, por confirmar a marginalização permanente da investigação portuguesa sobre Arqueologia e História de Roma, não é mitigada pela única referência incluída, pois alude a um colóquio cujas actas não foram publicadas ${ }^{14}$. Alguns clássicos da historiografia romana não estão incluídos na bibliografia, como sucede com The Roman Imperial Navy, de C. G. Starr, e o ainda muito útil Rome Beyond Imperial Frontiers, de Mortimer Wheeler. O volume termina com dois índices, analítico e de autores, que

${ }^{13}$ P. Petit, Histoire générale de l'Empire romain, 3, Le Bas-Empire, Paris, 1974, pp. 160-187.

${ }^{14}$ Trata-se do II Colóquio Internacional Epigrafia, Culto e Sociedade, que teve lugar em Sintra em 1995. 
contribuem para a fácil utilização da obra. No início foram incluídos para além do índice geral, uma tábua de siglas e abreviaturas e o indíce das ilustrações e dos mapas. Quanto às figuras inseridas na obra de Alejandro Molina, nem sempre possuem a qualidade gráfica desejável, mas perante as dificuldades de edição actuais não seria polido apontar esta circunstância como um factor negativo. A imagem que representa a construção de uma via romana era dispensável (fig. 36), pois mostra a estrutura da estrada de acordo com a famigerada e não provada teoria das quatro camadas de Nicolas Bergier ${ }^{15}$. Já em relação aos mapas a qualidade é francamente má, e julgo que teria valido a pena procurar conseguir melhor. A História exige sempre um suporte cartográfico eficiente. O mapa do Império Romano reflecte a expansão de Roma no final do século I, não à morte de Augusto (p. 36).

Tecerei agora breves considerações em torno de alguns pontos desta obra, desde logo importante pelas análises que inclui e pela permanente reflexão a que o leitor se sente obrigado por uma permanente dialéctica entre o presente e o passado. Alejandro Molina define o objectivo do estudo como un exhaustivo examen teórico acerca do que és la Romanización para compreender como Roma, entre Augusto e Caracalla, pudo conformar un orbis Romanus y, del mismo modo, se convirtió en la primera "aldea" e "imperio global" de la historia (pp. 30-31). O conceito de Romanização tem sido debatido com muito calor, sobretudo a partir de finais do século XX. Como reacção à visão tradicional e por vezes quase romântica da Romanização, surgiram propostas alternativas e críticas ${ }^{16}$, nalguns casos, como a pretendida crioulização comentada por Molina, anacrónicas interpretações da sociedade romana à luz de realidades de outras épocas e ideologicamente marcadas. Não deixa de ser interessante constatar que muitos defensores de uma visão negativa da Romanização, frequentemente dita pós-colonial, são acérrimos partidários de uma interpretação do multiculturalismo que, afinal, reproduz aquilo que condenam na Antiguidade. Alejandro Molina consegue mover-se com habilidade neste escorregadio terreno sem nunca abdicar de uma concepção positiva da Romanização e da coincidência do processo com o fenómeno da globalização. Opta, depois

${ }^{15}$ R. Chevallier, Les voies romaines, Paris, 1972, pp. 93-95.

${ }^{16}$ D. J. Mattingly (ed.), Dialogues in Roman Imperialism. Power, discourse and discrepant experience in the Roman Empire, Portsmouth (USA), 1997. Muito elucidativo. 
de uma longa exposição, por considerar o termo Romanização o mais adequado para identificar um processo complexo e dilatado no tempo, apesar das dificuldades que para muitos o termo implica, pela conotação imperialista e, para outros, por se tratar de uma criação intelectual: $L o$ concreto es que mientras no se conciba o invente otra "palabra" para caracterizar el desarrollo multidireccional de relaciones entre Roma y las provincias, debemos continuar con tal palabra (p. 68). Creio existir, realmente, um processo de transferência de elementos culturais e técnicos no interior do Império, produtor de uma aculturação progressiva na qual o modelo romano prevalece largamente, ainda que de início se exerça sobretudo sobre as elites provinciais. Com o tempo, a dinâmica da aculturação mudou a sociedade romana, com consequências irreversíveis e não poucas vezes traumatizantes. Como poderemos falar da Cristianização do Império sem admitir um processo de aculturação?

O entusiasmo que o autor demonstra a propósito de uma política pacífica e de integração a partir de Augusto (p. 259) suscita-me reticências. O factor domínio parece-me evidente e é tratada sem rodeios pelos ideólogos da época. Basta recordar o célebre trecho de Virgílio sobre a missão de Roma $^{17}$. Se a paz foi um dos contributos maiores da Romanização, não é menos verdade que as relações entre Romanos e provinciais, sobretudo com os não privilegiados com a civitas, estatuto que durante o século I abrangia apenas uns $8 \%$ do total da população ${ }^{18}$, estavam longe de se orientar para a fusão igualitária, como defende o autor. Talvez por isso mesmo, a discussão em aberto sobre o significado e alcance da Constitutio Antoniniana, compreensível segundo os princípios populistas da política severiana, divide ainda os investigadores, cujos argumentos nem sempre parecem convincentes (pp. 133-136). É sobre os mais de 90\% restantes que se desenvolvem as teses que criticam radicalmente o êxito da Romanização.

Creio que Molina teria feito bem em não diminuir as perturbações da ordem imperial, a ponto de falar de problemas menores na Judeia (p. 76), ainda que admita confrontos e a importância, essencial, do Exército (pp. 177-182). Uma questão central de tudo isto reside na determinação dos objectivos da Romanização. É evidente, como o autor sublinha, a impor-

${ }^{17}$ Virgílio, Aen., 874-853 (particularmente o verso 851: Tu, Romano, sê atento a governar os povos com o teu poder).

18 Os estudos demográfios são difíceis. O recenseamento de 28 a.C. registou 4063000 cidadãos, número que cresceu em 14, à morte de Augusto, para 4937000 . 
tância de um processo de imitação, motor da auto-romanização (pp. 7779), mas a existência de preocupações com uma política romanizadora dos estratos baixos das sociedades provinciais parece-me algo difícil de defender. Não só contrariava o pragmatismo romano, como não estava no horizonte ideológico das classes dirigentes, itálicas ou não, durante o Alto Império, incluindo figuras como o imperador Marco Aurélio ${ }^{19}$, sugerindo que nos nos acautelemos quanto a estas interpretações. Não quer isto dizer que o êxito do Império Romano tenha sido alcançado à revelia da maioria da população, êxito que como Molina bem demonstra, não podia assentar unicamente na força militar e na exploração, como sucedeu durante quase todo o período republicano.

A interpretação do Império Romano à luz de conceitos como o WorldSystem ou interpretando-o como um Império equivalente à globalização merece-me, como disse, reservas, que não se encontram no autor. $\mathrm{Na}$ Antiguidade os quatro grandes impérios consideravam-se todos universais e no centro do mundo. Nenhum deles era fundamental para os restantes, e bastaria isto para que qualquer comparação com a actualidade resultasse bastante forçada. Quem ousará hoje pretender que a Índia ou a China não têm interesse para o quotidiano ocidental? Molina refere-se com frequência à economia de mercado e ao liberalismo como garantes do processo romanizador (p. 146). Considero exagerada a interpretação do autor, pois enquanto que na actualidade a economia liberal assenta em teorias estabelecidas, associadas a uma filosofia política que a suporta, em Roma o liberalismo resultou da ausência de qualquer teoria económica, pelo que a intervenção estatal foi muito limitada e dirigida a aspectos de interesse estratégico.

Apenas mais algumas observações. A generalização de práticas alimentares deve ser considerada com cautela: as ânforas de azeite na Britânia ocorrem em ambientes militares ou nas villae ${ }^{20}$. Imaginar Roma rodeada de bidonvilles não me parece correcto (p. 198), considerando, por exemplo, o Subura no centro da cidade ${ }^{21}$. A propósito dos primórdios do culto imperial, para além da epígrafe de Gytheion (p. 184), o autor poderia

${ }^{19}$ Os Pensamentos não permitem dúvidas quanto à sua atitude: P. Petit, La paix romaine, Paris, 1967, pp. 160-161.

${ }^{20}$ C. C. Monfort, Britannia and the imports of Baetican and Lusitanian amphorae, Journal of Iberian Archaeology, Vol.0, 1998, pp. 159-170.

${ }^{21}$ L. Homo, Rome impériale et l'urbanisme dans l'antiquité, Paris, 1970, pp. 115-119, 482-484. 
ter incluído outra de Lisboa (CIL II 194), bastante significativa. Muito merecedora de atenção é a imitatio Alexandri (pp. 243-253) e o falhanço da política oriental de Roma, custosa sob todos os aspectos. A renúncia à Germânia, após o desastre de Teutoburgo, há dois mil anos, foi mais importante para o Ocidente do que as obstinadas tentativas orientais de um Império que, transformando-se e afastando-se gradualmente da concepção própria da cidade antiga, perdeu a energia e a vontade de fazer história ${ }^{22}$. Por aquilo com que concordo e por aquilo com que discordo, considero muito pertinente a leitura desta obra de Alejandro Bancalari Molina.

\section{Vasco Gil Mantas (Universidade de Coimbra)}

Rodrígez Alfageme, Ignacio, Aristófanes: escena y comedia, Madrid, Editorial Complutense, 2008, 421 pp. ISBN: 9788474919325

Os estudos sobre Comédia Grega Antiga e sobre aquele que constitui o seu principal testemunho, Aristófanes, passam a dispor de um título recente, de clara valia para os que se interessam pelo assunto. Refiro-me não só aos estudiosos de teatro grego provenientes dos Estudos Clássicos, mas também àqueles que se situam no âmbito dos Estudos Teatrais ou na execução prática da representação. De há muito conhecido pelos seus estudos sobre teatro grego, sobretudo cómico, Alfageme sistematiza e aprofunda, neste seu livro, resultados obtidos durante anos de investigação e de troca de opiniões com outros especialistas. De facto, uma das qualidades que importa sublinhar é a amplitude da bibliografia consultada, que permite uma visão diacrónica do progresso feito neste campo, como a identificação das questões mais polémicas que têm, a partir do séc. XIX, dividido opiniões. Deste percurso é imagem a longa e bem documentada bibliografia geral que encerra o volume. Por isso, este estudo aparece, antes de mais, como uma sistematização crítica e actualizada da erudição sobre Comédia Antiga e Aristófanes.

Uma simples consulta do índice é reveladora da hierarquia das opções tomadas pelo Autor. Ao longo de sete dezenas de páginas introdutórias, as questões ligadas ao género cómico e à produção de Aristófanes repartem-

${ }^{22}$ Todos os povos têm História, passiva para uns, activa para outros (die Geschichten machen), de acordo com o conceito alemão. 